\section{Let poor countries into rich research}

Researchers and decisionmakers from low-income countries should help to define the research priorities of universities in high-income countries (see Nature 514, 287; 2014). A strong guild of academics will aid the development of local solutions in poor countries that have little resilience to climate change, biodiversity loss or global health issues (see, for instance, C. Lachat et al. PLoS Med. 11, e1001593; 2014).

It is all too common for Western scientists to engage in research in the developing world that fails to benefit their locally based peers (see K. Chu et al. PLoS Med. 11, e1001612; 2014). This inequity could be rectified by introducing and enforcing strict ethical standards for funding and research. More-equitable metrics for research evaluation should also be developed (see, for example, E. Smith et al. BMC Med. Ethics 15, 42; 2014).

Carl Lachat Ghent University, Belgium.

Patrick Kolsteren Ghent University, Belgium; and Institute for Tropical Medicine, Antwerp, Belgium.

Dominique Roberfroid Institute for Tropical Medicine, Antwerp, Belgium.

carl.lachat@ugent.be

\section{Better modelling for the energy mix}

Contrary to Haewon McJeon and colleagues' implications (Nature 514, 482-485; 2014), natural shale gas and renewables are not necessarily competitors. They are driven by different policies and markets.

Over the next decade or so, natural gas can reduce coal consumption and can be rapidly dispatched to balance the intermittency of energy from wind and solar sources. In the longer term, say over the next
50 years, this mix can provide a path to an affordable, lowcarbon energy system, especially if it is configured as a backup or coupled with energy storage.

The low capital and high operating costs for natural gas combine well with the high capital and low operating costs of wind and solar. And by reducing the cost of climate mitigation, natural gas should motivate more-aggressive climate policies by governments. Gas is therefore promising because it is a powerful climate-mitigation option, not because it will prevent climate change in the absence of policy.

Moreover, the decisions that shape global energy choices are not always economic or technical (see B. K. Sovacool Nature 511, 529-530; 2014). Effective modelling needs to capture all of the complex and often non-quantitative forces that determine outcomes. These include energy security, trade policy, social equity, weather, distribution of resources, dynamic policies and unforeseen technological advances. Without these factors, the reliability of the long-term forecasts from McJeon et al. seems low.

Alexander Q. Gilbert Haynes and Boone, Washington DC, USA. Benjamin K. Sovacool Aarhus University, Denmark. benjaminso@hih.au.dk

\section{Funding plea for rural lab outreach}

The Imagine Project, set up last year by a group of Brazilian researchers (see go.nature.com/ yndqs1), is taking scientific knowledge out of the laboratory to share it with people from rural and indigenous communities. Despite their remarkable response, the initiative is still struggling to be funded.

Scientists and students from universities in Brazil, Morocco, Angola, Mexico and Peru are teaching, for example, molecular biology to Brazilian Indians, genome analysis to Peruvian Inca descendants and facts about solar energy to teenage land-workers (see go.nature.com/fdqnws).

Community members work and study on alternate days. The learners have, without exception, shown great enthusiasm. Their manual skills often exceed those of urban university students.

The project has been totally funded by Brazil's Federal University of Santa Catarina since its inception. Applications to corporate and governmental funding organizations have so far met with a dispiriting response.

The knowledge imparted is viewed as "too universal" - with no potential for immediate conversion into solutions for food, health or environmental problems. Policy-makers seem to regard the people who are engaged as too remote, too few and too 'invisible' to justify involving them in modern developments in science and technology.

André Ramos, Guilherme Razzera Federal University of Santa Catarina, Florianópolis, Brazil.

andre.ramos@ufsc.br

\section{Approximation aids handling of big data}

We need a radical shift in our approach to data analysis

- towards approximation.

Our technical capacity is being overtaken by the unprecedented rate of data generation by today's powerful instruments and computers (see H. Esmaeilzadeh et al. Commun. ACM 56, 93-102; 2013).

In my view, it is often more efficient to replace conventional, precise computations with scalable approximations that have tight error bounds - in algorithms and data structures, for example. This should be adequate for interpreting data, particularly when refining the explorative phase of an analysis. Researchers may ultimately still want to perform detailed analyses as indicated trends become clearer. And for some applications, approximation will not work at all.

Approximations, however, are already accepted in many realms, such as nextgeneration DNA sequencing (M. L. Metzker Nature Rev. Genet. 11,31-46; 2010). It is time to let mathematical ingenuity replace our obsession with precision.

Thomas Heinis Imperial College London, UK.

t.heinis@imperial.ac.uk

\section{EC grant applicants need fuller feedback}

The commitment of the European Commission (EC) to equitable and rigorous scientific review of the research it funds is undermined by the perfunctory quality of feedback to grant applicants. This denies investigators the opportunity to learn and improve from constructive expert criticism.

The commission's review procedures are time-consuming and costly. So, regardless of the final decision on funding, individual applicants should be privy to the full text of expert critiques of their proposals - not merely to a brief summary of the consensus ruling. The anonymous reviewers also deserve to be heard.

In my experience, these evaluation summary reports contain only vague comments, without constructive suggestions or scientific advice. For grant applications that can run to 70 pages, this minimal feedback seems inadequate.

The European Union cannot afford the current waste of intellectual resources and input into scientific development. Danuta Wasserman European Psychiatric Association, Strasbourg, France; and Karolinska Institute, Stockholm, Sweden.

danuta.wasserman@ki.se 